\title{
JUURNAL
}

of Health Inequalities

\section{Preventing sexually transmitted diseases (including HPV and HIV) in the context of premature sexual initiation, health promotion, and other related issues for gynaecological practice - a review}

\author{
Grażyna Jarząbek-Bielecka1, Magdalena Pisarska-Krawczyk2,3, Małgorzata Mizgier, Karolina Andrzejak5, \\ Stefan Sajdak ${ }^{6}$, Witold Kędzia' \\ 'The Clinic of Gynaecology of the Department of Perinatology and Gynaecology, The Division of Developmental \\ Gynaecology and Sexology of the Department of Perinatology and Gynaecology, Poznan University of Medical Sciences, \\ Poznan, Poland \\ ${ }^{2}$ Higher Vocational State School in Kalisz, Poland \\ ${ }^{3}$ Department of Maternal and Child Health, Poznan University of Medical Sciences, Poznan, Poland \\ ${ }^{4}$ Division of Nutrition, Department of Hygiene and Human Nutrition, University of Life Sciences, Poznan, Poland \\ ${ }^{5}$ Department of Human Nutrition and Hygiene, University of Life Sciences, Poznan, Poland \\ ${ }^{6}$ Clinic of Gynaecological Surgery, Poznan University of Medical Sciences, Poznan, Poland
}

\begin{abstract}
The trend for early sexual initiation has been growing in most countries of the world, estimated to now to be in the range around 15-18 years. Likewise, in those countries where an orthodox/conventional approach to premarital cohabitation is adopted, sexual initiation also begins earlier. This has resulted in increased rates of sexually transmitted diseases (STDs), including HIV infection, and increased risk of unplanned pregnancy. There is, therefore, an ever present need for sex education.
\end{abstract}

KEY WORDS: girls, STD, viral, infections, gynaecology.

ADDRESS FOR CORRESPONDENCE: Grażyna Jarząbek-Bielecka, The Clinic of Gynaecology of the Department of Perinatology and Gynaecology, Poznan University of Medical Sciences, 5 C Rokietnicka Street, 60-806 Poznan, Poland, e-mail: grajarz@o2.pl

...Sex is a certain mood, an experience to be lived through, and a physicality, but it also bears within itself a sense of responsibility, which mankind brings forth unto the world...

\section{INTRODUCTION}

Because of the decreasing age for sexual initiation and the rising threat of sexually transmitted diseases (STDs), coupled with other related and untoward consequences, most countries of the world conduct educational campaigns aimed at informing about how STDs occur and the means for their prevention. Attention is primarily focused on recommending abstinence at an early age, encouraging condom use, and general family planning.

Sexually transmitted diseases are a major health problem in the modern world, where $70 \%$ of STDs occur in young people aged below 20 years. Raising awareness of STDs and teaching prevention measures is thus particularly important for this age group. Education on such issues should therefore be introduced from 
an early age starting with the youngest primary school classes.

India has to contend with high rates of HIV and STDs, with the main reasons being reduced levels of awareness on how these diseases are spread among adolescents and the young, along with poor access to checkups. This situation has arisen because there is a general lack of understanding about pro-healthy behaviour/ lifestyles, especially those population groups that are vulnerable. Hindus rarely see a doctor about inflammatory diseases of the genital tract despite feeling discomfort. Sexual behaviour and taking part in prevention or education programmes is found to significantly depend on people's economic status, and therefore it is widely regarded that poorer countries should primarily target education at poorer social strata. In the USA, syphilis rates have steadily declined over the last 25 years, whilst there has been a concomitant rise in Chlamydia trachomatis infection. This is particularly dangerous to pregnant women because it can initiate premature birth or cause premature rupture of the amniotic sac. As a result of educational programmes carried out in Scotland, condom use in students has increased as a means of affording protection against STDs. Factors that play critical roles in STD infection are: age (most infections occur in those aged 15-24 years), race (Afro-Caribbean people are the most commonly affected, followed by Caucasians and Asians), and living location (most infections occur in large urban agglomerations).

Education teaches people to have regular check-ups and how to avoid infection, explains study outcomes and the principles of research, and improves personal contact with medical teams. Sex education began being taught in 1928 in Berlin, where the World League for Sexual Reform was launched to coordinate/promote knowledge on contraception, with a declared aim of introducing sex education into school curriculums; young people being more amenable for learning and changing their behaviour than adults. In Sweden, compulsory sex education in schools was introduced in 1945, whilst this was done in the late 1960s in the United States and European Union countries. According to the WHO, sexual education in most countries in fact starts too late, and the WHO has thereby issued appeals for youth programs to be started as early as appropriate before embarking on one's sexual life, but not later when young people are already sexually active. Educational programs should make people aware of the benefits of limiting the number of sexual partners and of using barrier-based contraceptives i.e. condoms. These programs should focus on normal sexual behaviour, whilst teaching understanding/respect of differences in sexual orientation. The most important factor affecting condom use is sexual orientation and the number of partners. There are countries in the world which particularly follow such aforementioned practices, for example Brazil, which has integrated medical services into youth training programmes [1-3]. By contrast, Belgian studies found that $10-20 \%$ of sexual contact with prostitutes is without barrier methods, which constitutes the main source of infection.

In Poland, the chief source of such information are the mass media, whereas the role played by the family in these matters is small, and school programmes provide only small and limited amounts of sex education. Attention should be focused on fostering appropriate attitudes towards persons suffering from infection or illness in these areas. Indeed, $2 / 3$ of teenagers are afraid to make contacts with persons infected with HIV, thereby illustrating' their ignorance about how it can be caught. Studies on Polish children and adolescents have demonstrated many gaps in knowledge about healthy behaviour: 65\% undertake too little physical activity, $74 \%$ do not eat vegetables, $25 \%$ drink alcohol regularly, and $18 \%$ use psychoactive substances. Dealing with sexual problems in Poland is still taboo in some circumstances, arising from ignorance on matters such as family planning, which results in many people suffering whenever problems in sexual dysfunction occur. It is also unfortunate that patients complain that their physicians never enquire about any sexual problems that they may have. In Poland, as in other countries, there is a need to promote health regarding doing more physical activity, knowing about healthy nutrition, the basics of hygiene relating to sexual behaviour, and about methods of contraception/birth control. The latter can be defined as ways of avoiding becoming pregnant (i.e. preventing fertilisation of the egg); the word itself originates from the term anti conteptio meaning against conception. Contraception prevents unplanned pregnancies and provides freedom of choice for the right moment to become a parent. It protects against sexually transmitted infections through barrier methods. As alluded to previously, the age of sexual initiation is falling throughout the world and is currently estimated at 15-18 years. Likewise, in countries with conventional attitudes to sex, couples living together before marriage leads to an early sexual initiation. This has resulted in increased rates of HIV infection and other sexually transmitted diseases, both in African countries as well as in the developed world. In addition to the risk of contracting STDs is the problem of unplanned pregnancy. There is an ever present need for pro-health sex education [1-4]. Although the body is protected by the immune system, most people will experience inflammation problems during their lives. For girls, preventive cytological testing is required and due consideration should be given to vaccinating against the oncogenic strains of HPV (human papilloma virus). An early sexual initiation, risk bearing sexual behaviour, and frequent changes of partners, not only lead to infections being transmitted, but also allow opportunistic flora to be introduced into the female's external genitalia, the internal parts of the vagina, and 
into the colon. In this regard, preventing STDs and using barrier contraceptives (i.e. condoms) are methods for preventing gynaecological disease in adolescents. In addition, immature metaplasia of the cervical epithelium in girls renders them particularly vulnerable to carcinogenic risk factors of cervical cancer arising via sexually transmitted infections (e.g. some serotypes of HPV). The anatomical features and physiological conditions of the genitals are such that infections, and sexually transmitted ones, occur for the following reasons: the close proximity and moisturisation around the mouth of the urethra and anus, and early sexual initiation and frequent changes of partners arising from human behaviour/lifestyle, which is influenced by socio-economic, psychological, and cultural factors [1-5]. Such teenage diseases are a major cause of concern for healthcare professionals and society in general [6-9]. Among the risk factors for developing cervical cancer, the most significant is via chronic infection with the oncogenic human papilloma virus (HPV); principally the 16 and 18 types or others that are highly carcinogenic [10-12]. Other risk factors are age, early age of sexual initiation, large numbers of sexual partners, many births, smoking cigarettes for long periods, low socioeconomic status, and cervical intraepithelial neoplasia whenever confirmed by investigation. Likely risk factors for cervical cancer are long-term use of hormone-based contraceptives, diets low in antioxidants, HIV infection, and untreated vaginitis caused by, amongst others, Chlamydia trachomatis and Neisseria gonorrhoea.

Papillomaviruses cause genital warts and abnormal tissue growth. There are over 100 types of papillomavirus, and only some are linked to genital cancers. The HPV 16 and 18 types are responsible for around $70 \%$ of cervical cancers, whilst HPV types 6 and 11 cause about 75-90\% of genital warts. Word population surveys for HPV in women have demonstrated that HPV 16 and 18 are the dominant oncogenes for cervical cancer [11-15]. HPVs exhibit specific tropism for squamous epithelium of the skin and mucous membranes where they elicit changes; however, they are resistant to the local immune system and cause viraemia or general infection. Despite the low or undetectable levels of antibodies after an infection, resulting from the adaptive immune response to $\mathrm{HPV}$, it should be noted that the immune response to natural infection does not always protect against any re-infection, nor whether a previous infection conveys a lifelong immunity. A vaccine against oncogenic HPV serotypes has now been introduced, which has gained licences in many countries [16-19]. Routine vaccinations of teenagers aged 11-12 years and vaccination of older girls and women against HPV has been recommended by the Polish Gynaecological Society (PTG) and the Polish Society for the Prevention of HPV Infection (HPV-PTPZ) [17, 18]. The former estimates that vaccinating teenagers and young women against HPV can reduce the total number cervical cancer cases by 76-96\% within $15-20$ years after starting the vaccination. Both societies emphasise the high efficacy of HPV vaccines, which has been at $100 \%$ within the last five years of monitoring clinical trials. The PTPZ-HPV, which prepared its recommendations in collaboration with other societies (i.e. the Polish Paediatric Society, the Polish Society of Family Medicine, and the Polish Society for Gynaecological Oncology), also recommends vaccinating girls and women aged 13-26 years, boys aged 9-15 years, and girls aged 9-11 years.

Notwithstanding, it is unfortunate that in recent times the rates of HIV infections have increased. HIV is a human immunodeficiency virus that weakens the human immune system, thus making the body vulnerable to contracting some very serious diseases. After several years of being infected with HIV, the immune system becomes very weak. The virus is capable of leading to AIDS; however, it must be remembered that a person infected with HIV does not necessarily have AIDS. Some of the conditions indicating that AIDS is present are:

- TB (tuberculosis),

- recurrent salmonellosis,

- oesophageal candidiasis,

- pneumonia,

- cervical cancer

\section{ROUTES OF HIV INFECTION}

HIV can be transmitted by:

- contact of infected blood with the blood of healthy people; doctors are required to use sterile instruments (e.g. syringe needles),

- blood transfusion,

- sexual contact (including oral sex),

- through semen and the cervical mucus,

- via the mother's milk, thus in such suspected cases breastfeeding should be excluded,

- foetal infection,

- by using razors or needles (e.g. in tattooing).

At the beginning of the AIDS epidemic, the virus was most often transmitted via blood transfusions, transplants, and by drug addicts who were sharing the same syringe.

\section{HIV - EARLY INFECTION AND CLINICAL LATENCY STAGE}

HIV's asymptomatic period can take up to 15 years, and during this time people can experience no symptoms or only mild ones. It is during this period that another sexual partner can easily become infected if the carrier is unaware of being themselves infected.

The early acute stage of HIV infection consists of the following symptoms which quickly arise after infection, and are similar to intense flu-like symptoms, but whose consequences are very much more serious. Symptoms most commonly being: fever, swollen glands (lymphadenopathy), sore throat, muscle and joint aches and pains. 


\section{PRINCIPLES OF PREVENTION OF HIV INFECTION}

Having casual sex, especially without barrier protection (condoms) carries a serious risk of viral transmission and is analogous to sharing the same needle with other persons. Why then is using condoms so important during intercourse? The condom is the only contraceptive means for affording protection, not only as a contraceptive, but also against STDs and HIV infections as mentioned beforehand. Using condoms gives 80-95\% protection against infections that could have arisen in instances of unprotected coitus. Viral detection is performed by measuring anti-HIV antibodies; their appearance being a natural immune response to infection. There are also tests available for measuring the p24 antigen in blood that appears prior to the antibody response which can be performed, free of charge, at consulting and diagnostic stations/points managed by the National AIDS Centre. Every major city has one such station.

\section{AIDS TREATMENT}

At the moment there are no effective cures for HIV infection; the only possible solutions being to gradually inhibit viral development and in obstructing viral penetration into cells. To these ends different formulations are used. Such therapy minimises blood levels of this virus and restores the immune system thereby allowing the patient to live for many years. In Poland, as in other European Union countries, this is publically funded by the respective National Health Services.

\section{PREVENTION, CDC RECOMMENDATIONS}

The surest way of avoiding STDs is to abstain from sexual contact (whether vaginal, anal, or oral) or to remain in a long-term monogamous relationship with an uninfected partner. Before engaging in sex, it is advisable to perform STD tests that include those for detecting HIV. Whenever sexual partners are strangers or are known to already have STDs, a condom should always be used. Vaccinations are also an effective means for preventing STDs, but apart from Hepatitis B and HPV their availability is limited. Male condoms are an effective method for prevention. Female condoms, however, require further testing even though they share similar protective features with the male ones. Using spermicides alone is not recommended for protection against STDs such as HIV, Gonorrhoea, and Chlamydia; their routine use can increase the risk of transmitting HIV. Likewise, condoms lubricated with Nonoxynol-9 do not increase the margin of safety.

\section{METHODS FOR PREVENTING STDS}

Condoms are effective against Gonorrhoea, Trichomoniasis, Chlamydias, and HIV.

Condoms are ineffective against HSV, HPV, syphilis, and genital ulcerative diseases.
Condoms have low effectiveness against diseases transmitted by dermal contact.

Latex is a better material for condoms than polyurethane or any other synthetics.

Latex is often allergenic, but is more effective than other materials.

\section{CONCLUSIONS}

This review indicates that premature sexual initiation is responsible for many important medical and social problems thereby arising. Sexually transmitted diseases need to be prevented, which includes ones such as HPV and HIV infection. Appropriate sex education and pro-health policies need to be implemented at all levels $[19,20]$.

\section{DISCLOSURE}

Authors report no conflict of interest.

\section{References}

1. Lara-Torre E, Hertweck SP. Leczenie zachowawcze problemów ginekologicznych u dzieci i nastolatek [Conservative treatment problems gynecological in children and teens]. In: Bieber EJ, Sanfilippo JS, Horowitz IR (eds.). Ginekologia kliniczna. Elsevier Urban \& Partner, Wrocław 2009

2. Pawlaczyk M, Jarząbek G, Pawlaczyk M i wsp. Choroby zapalne sromu i pochwy u dziewcząt (vulvovaginitis) w różnych okresach rozwojowych [Inflammatory diseases vulva and vagina in girls (vulvovaginitis) in different developmental periods]. Ginekol Prakt 2006; 14: 116-118.

3. Saracen A. Health behaviours of high school students. Hygeia Public Health 2010; 1: 70-73.

4. Verhelst R, Verstraelen H, Claeys G, et al. Comparison between Gram stain and culture for the characterization of vaginal microflora: definition of a distinct grade that resembles grade I microflora and revised categorization of grade I microflora. BMC Microbiol 2005; 14: 61.

5. Reid G, Bruce AW. Selection of Lactobacillus strains for urogenital probiotic applications. J Infect Dis 2001; 183 (Suppl 1): S77-S80.

6. Garden AS. Vulvovaginitis and other common childhood gynaecological conditions. Arch Dis Child Educ Pract Ed 2011; 96: 73-78.

7. Sowińska E, Lazar W, Menkiszak J, et al. Lichen sclerosus in girls-risk group for development of vulvar neoplasms in women. Ginekol Pol 1993; 64: 305-309.

8. Woynarowska B, Izdebski Z, Kołoło H, Mazur J. Inicjacja seksualna i stosowanie prezerwatyw oraz innych metod zapobiegania ciąży przez młodzież 15-letnią w Polsce i w innych krajach [Sexual initiation and use of condoms and other methods of prevention pregnant by the young 15-year-old in Poland and in other countries]. Ginekol Pol 2004; 75: 621-632.

9. Pawlaczyk M, Grys E. Prevalence of bacterial vaginosis in adolescent girls. Acta Dermatovenerol Croat 2001; 9: 279-281.

10. Schiffman M, Castle PE, Jeronimo J, et al. Human papillomavirus and cervical cancer. Lancet 2007; 370: 890-907. 
11. Muñoz N, Bosch FX, de Sanjosé S, et al. Epidemiologic classification of human papillomavirus types associated with cervical cancer. N Engl J Med 2003; 348: 518-527.

12. Smith JS, Lindsay L, Hoots B, et al. Human papillomavirus type distribution in invasive cervical cancer and high-grade cervical lesions: a meta-analysis update. Int J Cancer 2007; 121 : 621-632.

13. Viscidi RP, Snyder B, Cu-Uvin S, et al. Human papillomavirus capsid antibody response to natural infection and risk of subsequent HPV infection in HIV-positive and HIV negative women. Cancer Epidemiol Biomarkers Prev 2005; 14 283-288.

14. Schwarz TF, Leo O. Immune response to human papillomavirus after prophylactic vaccination with AS04-adjuvanted HPV16/18 vaccine: improving upon nature. Gynecol Oncol 2008; 110 (3 Suppl 1): S1-10.

15. Harper D, Gall S, Naud P, et al. Sustained immunogenicity and high efficacy against HPV-16/18 related cervical neoplasia: longterm follow up through 6.4 years in women vaccinated with Cervarix $^{\mathrm{Tm}}$ (GSKs HPV 16/18 AS04 candidate vaccine). Gynecol Oncol 2008; 109: 158-189.

16. FUTURE II Study Group. Quadrivalent vaccine against human papillomavirus to prevent high-grade cervical lesions. N Engl J Med 2007; 356: 1915-1927.

17. Spaczyński M, Nowak-Markwitz E, Basta A, et al. Polish Gynecology Society Guidelines for human papillomavirus (HPV) vaccine use to prevent cervical cancer. Ginekol Pol 2007; 78 (Suppl 1-6): 185-190.

18. Majewski S, Sikorski M. Rekomendacje Polskiego Towarzystwa Profilaktyki Zakażeń HPV (PTPZ-HPV) dotyczące stosowania profilaktycznych szczepionek przeciw HPV [Recommendations Polish Society HPV Infection Prevention (PTPZ-HPV) concerning the application of prophylactic HPV vaccines]. Przew Lek 2008; 1: 222-227.

19. Jarząbek-Bielecka G, Pawlaczyk M, Pisarska-Krawczyk M, et al. Sexually transmitted diseases in adolescents. Curr Gynecol Oncol 2015; 13: 20-26.

20. Mizgier M, Jarząbek-Bielecka G, Andrzejak K, et al. Health promotion in context of the importance of diet and physical activity in prevention and treatment of diabetes. Polish Review of Health Sciences 2013; 3.

\section{AUTHORS' CONTRIBUTIONS}

GJB, MPK, SS prepared the research concept and design of the publication. MM and KA collected data. MPK analysed data. GJB and MPK wrote the article. SS and WK finally approved it. 